\title{
A Novel Clinical Nomogram for Predicting Lymph Node Metastasis in Ovarian Cancer: A SEER Analysis and External Validation in a Tertiary Center
}

\section{Guiping Zhang}

General Hospital of Northern Theatre command

Wei Ren ( $\square$ qrenwei@hotmail.com )

General Hospital of Northern Theatre command

\section{Research Article}

Keywords: ovarian carcinoma, lymph node metastases, nomogram, internal and external validation

Posted Date: November 19th, 2021

DOI: https://doi.org/10.21203/rs.3.rs-1004467/v1

License: (c) (1) This work is licensed under a Creative Commons Attribution 4.0 International License.

Read Full License 


\section{Abstract \\ Introduction}

The aim of the study is to investigate the risk factors for developing lymph node metastases (LNM) in cases diagnosed as a presumed early-stage ovarian carcinoma (OC).

\section{Methodology}

Information of patients who had been diagnosed as OC in 2018 was obtained from the SEER database. We enrolled 104 OC patients in General Hospital of Northern Theatre Command for external validation. A logistic regression was conducted to determine the independent predictors for $L N M$, which were used for establishing a nomogram. In order to evaluate the reliability of nomogram, we applied a receiver operating characteristic curve (ROC) analysis, calibration curves and plotted decision curves.

\section{Results}

We found that age $(\geq 70, O R=0.544, p=0.022)$, histology type (Mucinous carcinoma, $O R=0.390, p=0.001$; Endometrioid carcinoma, $\mathrm{OR}=7.946, \mathrm{p}=0.053$; Others, $\mathrm{OR}=2.400, \mathrm{p}=0.040$ ), histology grade (Grade II, $\mathrm{OR}=2.423, \mathrm{p}=0.028$; Grade III, $\mathrm{OR}=1.982, \mathrm{p}=0.152$; Grade IV, $\mathrm{OR}=1.594, \mathrm{p}=0.063$ ) and preoperative serum CA125 level (positive, OR=2.236, $p=0.001$ ) were all significant predictors of $L N M$. The AUC of the model training cohort, internal validation cohort, and external validation cohort were $0.78,0.79$ and 0.76 respectively. The calibration curves showed that the predicted outcome fitted well to the observed outcome in the training cohort $(p=0.825)$ internal validation cohort $(p=0.503)$, and external validation cohort ( $p=0.108)$. The decision curves showed the nomogram had more benefits than the All or None scheme if the threshold probability is $>50 \%$ and $<100 \%$ in training cohort and internal validation cohort, $>30 \%$ and $<90 \%$ in the external validation cohort.

\section{Conclusion}

The multivariate logistic regression showed that age, histology type, histology grade and preoperative serum CA125 level were all significant predictors of LNM. The nomogram established using the above variables had great performance for clinical applying.

\section{Introduction}

Annually worldwide, there are 230000 women diagnosing as ovarian carcinoma (OC) and 150000 patients die. Although the incidence of $\mathrm{OC}$ was is the third of gynecological malignancies, its mortality rate is the highest. In recent years, the incidence of $O C$ has gradually increased[1, 2, 3]. Because of late detection, $70 \%$ of OC patients present with advanced stages upon diagnosis[4]. OC can be transferred by 
intraperitoneal route, lymphatic route, and blood-borne route. Previous studies showed that up to $15 \%$ of OC have positive lymph node metastases (LNM), which would significantly influence the lifetime of OC[5]. Whereas, there were about $80 \%$ of cases unnecessary if the lymph node dissection is routine in presumed early-stage $\mathrm{OC}[6,7,8]$. Moreover, dissection of lymph node would increase occurrence of complications, including infection, formation of lymphocyst, which might significantly influence the quality of life[9, 10, 11]. Consequently, identifying $O C$ cases with positive lymph node metastases (LNM) would help the oncologist institute treatment decisions which will benefit the prognosis of OC.

The aim of the study is to investigate the risk factors for developing LNM in cases diagnosed as a presumed early-stage OC. In our study, we used logical regression to construct a nomogram for predicting LNM in OC cases based on the SEER database and external validation in a Gynecological oncology Center.

\section{Materials And Methods}

\section{Study Population and Data collection in SEER database}

Information of patients who had been diagnosed as OC in 2018 was obtained from the SEER database using SEER ${ }^{\star}$ Stat software. In order to access the data of SEER, we obtained signed authorization. The following were the inclusion criteria: (1) Site recode ICD-0-3/WHO 2008: Ovary, (2) year of diagnosis: 2018. The exclusion criteria were as following: (1) information missing of LNM, tumor size, race, marital status, histology, or tumor grade, (2) no first tumor.

Following the processing flowchart shown in Figure 1,921 patients with OC were enrolled in our study. At a ratio of 7:3, we randomly divided the 921 cases into a training cohort $(n=644)$ and validation cohort $(n$ $=277$ ). We collected the variables including age, race, insure, marriage, laterality, histology type and grade, tumor size, preoperative serum CA125 level and lymph nodes positive.

\section{External Validation data}

The clinical Data of 104 OC patients were extracted from electronical database of the General Hospital of Northern Theatre Command. This study was approved by the Institutional Review Board of the General Hospital of Northern Theatre Command (ID:2020016). Because the study was retrospective and observational, the board waived the patients' informed consent. Inclusion criteria: (1) The OC was primary, and diagnosed by postoperative pathology, (2) The patients did not receive preoperative biological therapy or chemoradiotherapy, (3) The clinical data were complete.

\section{Statistical analysis}

The categorical and continuous data were expressed as percentage and mean \pm SD respectively. For categorical variables, we conducted $t$ test or Mann-Whitney $U$ test to make comparisons between the groups while for continuous variables, chi-square test or Fisher's exact tests were used. To develop a wellreliable nomogram model predicting the risk of LNM, our nomogram was built using the training cohort 
with 644 patients, validated internally using the 277 patients and then validated externally using the 104 patients in the General Hospital of Northern Theatre Command. In order to check multicollinearity between clinical variables, we used the variance inflation factor (VIF) and tolerance. A logistic regression was conducted to determine the independent predictors for LNM, which were used for establishing a nomogram. In order to evaluate the reliability and the net benefit of nomogram, we applied a receiver operating characteristic curve (ROC) analysis, calibration curves and plotted decision curves. We considered statistically significant if the $p$ value was less than 0.05 . we used the statistical packages $R$ (The R Foundation; http://www.r-project.org; version 3.4.3) and Empower (R) to analyze the Data (www.empowerstats.com, X\&Y solutions, inc. Boston, Massachusetts).

\section{Results}

\section{Demographic characteristics}

In our study, we enrolled 644 and 277 cases into the training cohort and the validation cohort. There was no difference in various indicators between the two cohorts $(P>0.05$, Table 1$)$. Most of the patients were white $(76.9 \%)$, the histological type was serous carcinoma (44.4\%), the most histological grade was G3 (43.8\%), $66.6 \%$ of the patients were with positive serum CA125 and $77.6 \%$ of the patients were with positive LNM. 
Table 1

Characteristics of patients in the training and validation cohorts

\begin{tabular}{|c|c|c|c|}
\hline Characteristics & $\begin{array}{l}\text { Training cohort } \\
(\mathrm{N}=277)\end{array}$ & $\begin{array}{l}\text { Internal Validation cohort } \\
(\mathrm{N}=644)\end{array}$ & $\mathbf{P}$ \\
\hline Age (years) & & & 0.985 \\
\hline$\leq 40$ & $22(7.9 \%)$ & $51(7.9 \%)$ & \\
\hline $40-70$ & 199(71.8\%) & 458(71.1\%) & \\
\hline$\geq 70$ & $56(20.2 \%)$ & $135(21.0 \%)$ & \\
\hline Insurance & & & 0.317 \\
\hline Insured & 193(69.7\%) & $427(66.3 \%)$ & \\
\hline Uninsured and others & $84(30.3 \%)$ & 217(33.7\%) & \\
\hline Race & & & 0.473 \\
\hline White & $220(79.4 \%)$ & 488(75.8\%) & \\
\hline Black & $20(7.2 \%)$ & $52(8.1 \%)$ & \\
\hline Other & $37(13.4 \%)$ & 104(16.1\%) & \\
\hline Marital status & & & 0.552 \\
\hline Married & $212(76.5 \%)$ & $481(74.7 \%)$ & \\
\hline Unmarried and others & $65(23.5 \%)$ & 163(25.3\%) & \\
\hline Histology & & & 0.751 \\
\hline Serous adenocarcinoma & $123(44.4 \%)$ & $286(44.4 \%)$ & \\
\hline Mucinous carcinoma & $26(9.4 \%)$ & $56(8.7 \%)$ & \\
\hline Endometrioid carcinoma & 74(26.7\%) & $158(24.5 \%)$ & \\
\hline Others & $54(19.5 \%)$ & $144(22.4 \%)$ & \\
\hline Differentiation & & & 0.358 \\
\hline Grade I & $66(23.8 \%)$ & $143(22.2 \%)$ & \\
\hline Grade /l & 49(17.7\%) & $89(13.8 \%)$ & \\
\hline Grade III & $112(40.4 \%)$ & $291(45.2 \%)$ & \\
\hline Grade IV & $50(18.1 \%)$ & 121(18.8\%) & \\
\hline Laterality & & & 0.970 \\
\hline Left & 129(46.6\%) & $305(47.4 \%)$ & \\
\hline
\end{tabular}




\begin{tabular}{|llll|}
\hline Characteristics & $\begin{array}{l}\text { Training cohort } \\
\mathbf{( N = 2 7 7 )}\end{array}$ & $\begin{array}{l}\text { Internal Validation cohort } \\
\mathbf{( N = 6 4 4 )}\end{array}$ & P \\
\hline Right & $125(45.1 \%)$ & $285(44.3 \%)$ & \\
\hline Unspecial & $23(8.3 \%)$ & $54(8.4 \%)$ & 0.645 \\
\hline Tumor size (mm) & $110.27 \pm 67.28$ & $112.55 \pm 69.65$ & 0.175 \\
\hline Preoperative serum CA125 level & & & \\
\hline Positive & $195(70.4 \%)$ & $418(64.9 \%)$ & 0.869 \\
\hline Negative & $38(13.7 \%)$ & $119(18.5 \%)$ & \\
\hline Not documented & $44(15.9 \%)$ & $107(16.6 \%)$ & \\
\hline lymph node metastasis & & & \\
\hline Negative & $61(22.0 \%)$ & $145(22.5 \%)$ & \\
\hline Positive & $216(78.0 \%)$ & $499(77.5 \%)$ & \\
\hline
\end{tabular}

\section{Nomogram Construction}

We used the univariate logistic regression to analyze the association between age, insurance, race, marital status, histology type, histology grade, laterality, tumor size, preoperative serum CA125 level and LNM. We found that histology type (Mucinous carcinoma, $\mathrm{OR}=0.346, \mathrm{p}<0.001$; Endometrioid carcinoma, $\mathrm{OR}=11.555, \mathrm{p}=0.018$; Others, $\mathrm{OR}=2.807, \mathrm{p}=0.007$ ), histology grade (Grade II, OR=6.059, $\mathrm{p}<0.001$; Grade III, $\mathrm{OR}=6.658, \mathrm{p}<0.001$; Grade IV, $\mathrm{OR}=1.894, \mathrm{p}=0.005$ ) and preoperative serum CA125 level (positive, $\mathrm{OR}=2.749, \mathrm{p}<0.001)$ were all significant predictors of LNM (Table2). 
Table 2

Univariate and multivariate logistic regression model for predicting lymph node metastasis in the model of training cohort

\begin{tabular}{|c|c|c|c|c|}
\hline \multirow[t]{2}{*}{ Variables } & \multicolumn{2}{|l|}{ Univariate analysis } & \multicolumn{2}{|l|}{ Multivariate analysis } \\
\hline & OR $(95 \% \mathrm{Cl})$ & $\begin{array}{l}P \\
\text { value }\end{array}$ & OR $(95 \% \mathrm{Cl})$ & $\begin{array}{l}\mathrm{P} \\
\text { value }\end{array}$ \\
\hline \multicolumn{5}{|l|}{ Age (years) } \\
\hline$\leq 40$ & 1 & & 1 & \\
\hline $40-70$ & $1.344(0.566,3.190)$ & 0.503 & $0.530(0.195,1.439)$ & 0.213 \\
\hline$\geq 70$ & $0.791(0.493,1.269)$ & 0.331 & $0.544(0.323,0.917)$ & 0.022 \\
\hline \multicolumn{5}{|l|}{ Insurance } \\
\hline Insured & 1 & & 1 & \\
\hline Uninsured and others & $0.787(0.527,1.176)$ & 0.243 & $0.805(0.515,1.256)$ & 0.339 \\
\hline \multicolumn{5}{|l|}{ Race } \\
\hline White & 1 & & 1 & \\
\hline Black & $1.445(0.894,2.337)$ & 0.133 & $1.213(0.708,2.079)$ & 0.483 \\
\hline Other & $1.160(0.542,2.481)$ & 0.702 & $0.964(0.406,2.286)$ & 0.933 \\
\hline \multicolumn{5}{|l|}{ Marital status } \\
\hline Married & 1 & & 1 & \\
\hline Unmarried and others & $0.922(0.600,1.418)$ & 0.712 & $0.844(0.523,1.362)$ & 0.487 \\
\hline \multicolumn{5}{|l|}{ Histology } \\
\hline Serous adenocarcinoma & 1 & & 1 & \\
\hline Mucinous carcinoma & $0.346(0.211,0.567)$ & 0.000 & $0.390(0.227,0.669)$ & 0.001 \\
\hline Endometrioid carcinoma & $11.555(1.526,87.466)$ & 0.018 & $7.946(0.977,64.622)$ & 0.053 \\
\hline Others & $2.807(1.327,5.939)$ & 0.007 & $2.400(1.1041,5.534)$ & 0.040 \\
\hline \multicolumn{5}{|l|}{ Differentiation } \\
\hline Grade I & 1 & & 1 & \\
\hline Grade II & $6.059(3.129,11.733)$ & 0.000 & $2.423(1.098,5.345)$ & 0.028 \\
\hline Grade III & $6.658(2.954,15.004)$ & 0.000 & $1.982(0.777,5.056)$ & 0.152 \\
\hline Grade IV & $1.894(1.209,2.967)$ & 0.005 & $1.594(0.976,2.605)$ & 0.063 \\
\hline Laterality & & & & \\
\hline
\end{tabular}




\begin{tabular}{|llllll|}
\hline Variables & Univariate analysis & & & \multicolumn{2}{l|}{ Multivariate analysis } \\
\cline { 2 - 2 } & OR $(95 \% \mathrm{Cl})$ & $\begin{array}{c}\mathbf{P} \\
\text { value }\end{array}$ & & OR $(95 \% \mathrm{Cl})$ & $\begin{array}{c}\mathbf{P} \\
\text { value }\end{array}$ \\
\hline Left & 1 & & 1 & \\
\hline Right & $1.081(0.550,2.139)$ & 0.815 & & $1.067(0.498,2.284)$ & 0.868 \\
\hline Unspecial & $1.117(0.564,2.214)$ & 0.751 & & $1.148(0.535,2.463)$ & 0.724 \\
\hline Tumor size $(\mathrm{cm})$ & $1.001(0.999,1.004)$ & 0.292 & & $0.999(0.996,1.003)$ & 0.636 \\
\hline $\begin{array}{l}\text { Preoperative serum CA125 } \\
\text { level }\end{array}$ & & & & \\
\hline Negative or Not documented & 1 & & & 1 & \\
\hline Positive & $2.749(1.753,4.309)$ & 0.000 & $2.236(1.373,3.641)$ & 0.001 \\
\hline
\end{tabular}

Using the multivariate logistic regression, we analyzed the association between age, insurance, race, marital status, histology type, histology grade, laterality, tumor size, preoperative serum CA125 level and LNM (Table 3). We found that age $(\geq 70, O R=0.544, p=0.022)$, histology type (Mucinous carcinoma, $\mathrm{OR}=0.390, \mathrm{p}=0.001$; Endometrioid carcinoma, $\mathrm{OR}=7.946, \mathrm{p}=0.053$; Others, $\mathrm{OR}=2.400, \mathrm{p}=0.040$ ), histology grade (Grade II, OR=2.423, $p=0.028$; Grade III, OR=1.982, $p=0.152$; Grade IV, OR=1.594, $p=0.063$ ) and preoperative serum CA125 level (positive, $\mathrm{OR}=2.236, \mathrm{p}=0.001$ ) were all significant predictors of LNM (Table2). In addition, we found the tolerance was $>0.1$ and VIF was $<10$ for the predictors, suggesting no collinearity among these independent variables (Supplement Table 1). Based on the above risk factors, we established the nomogram for predicting LNM.

Table 3

Performance of the nomogram in predicting lymph node metastasis in the training cohorts

\begin{tabular}{|llllllll|}
\hline $\begin{array}{l}\text { Performance } \\
\text { parameter }\end{array}$ & AUC & Accuracy & Specificity & Sensitivity & PLR & NLR & DOR \\
\hline Nomogram 0.77 & 0.72 & 0.73 & 0.72 & 2.69 & 0.38 & 7.02 \\
\hline AUC: Area Under the Curve & & & & & \\
\hline PLR: positive likelihood ratio & & & & & & \\
\hline NLR: negative likelihood ratio & & & & & \\
\hline DOR: Diagnostic Odds Ratio & & & & & \\
\hline
\end{tabular}




\section{Nomogram Validation}

\section{Internal Validation}

The AUC of the model training cohort and validation cohort were 0.78 (figure $3 \mathrm{~A}$ ) and 0.79 (figure3B) respectively, which indicated favorable discrimination. The calibration curves showed that the predicted outcome fitted well to the observed outcome in the training cohort $(p=0.825$, figure3D) and validation cohort ( $p=0.503$, figure3E). The decision curves showed the nomogram had more benefits than the All or None scheme if the threshold probability is $>50 \%$ and $<100 \%$ in training cohort and validation cohort (figure3G, H). The AUC, accuracy, specificity, sensitivity, PLR, NLR, DOR were 0.77, 0.72, 0.73, 0.72, 2.69, $0.38,7.02$ respectively (Table3).

\section{External Validation}

A total of 104 OC patients in the Department of Gynecology, General Hospital of Northern Theatre Command were collected. In the age, the proportion of $\leq 40,40-70$ and $\geq 70$ was $11.5 \%, 49.0 \%$ and $39.4 \%$ respectively. Most of the patients were white $(72.1 \%)$, the insured was $62.5 \%$, the married was $70.2 \%$, the positive serum CA125 was $58.7 \%$, the positive LNM was $78.8 \%$. In the differentiation, the proportion of grade I, grade II, grade III and grade IV was $33.7 \%, 18.3 \%, 37.5 \%$, and $10.6 \%$ respectively. In the histology type, the proportion of serous adenocarcinoma, mucinous carcinoma, endometrioid carcinoma and others was $26.0 \%, 17.3 \%, 28.8 \%$, and $27.9 \%$ respectively. The mean tumor size was $120.67 \pm 74.15 \mathrm{~mm}$. Characteristics of patients are shown in supplementary Table 2. The AUC of the external validation cohort were 0.76 (figure3C), which indicated favorable discrimination. The calibration curves showed that the predicted outcome fitted well to the observed outcome in the external validation cohort $(p=0.108$, figure3F). The decision curves showed the nomogram had more benefits than the All or None scheme if the threshold probability is $>30 \%$ and $<90 \%$ in the external validation cohort (figure 3 I).

\section{Discussion}

More than $70 \%$ of OC patients were diagnosed as late stage because of the insidious progress and not obvious symptoms early, which leads to the 5 -year survival rate is only $30 \%-40 \%[4]$. The issue of LNM in $\mathrm{OC}$ has a particular interest among gynecological oncologists worldwide, because the LNM was with high occurrence and would affect the prognosis of $O C[1,12,13,14]$. Nasioudis et al. have found that the rate of LNM was about $3.3 \%-14 \%$ in early OC and as high as $40 \% \sim 73.7 \%$ in late $\mathrm{OC}[15,16]$. Moreover, it was observed that plenty of cases diagnosed as presumed early-stage OC already have LNM. Therefore, all these mis-staging cases are at risk for poor long-term prognosis. In consideration of the influence of LNM on prognosis, routine lymph node resection in early OC patients has been performed by most surgeons. Whereas, routine performance of lymph node resection might lead to overtreatment in a significant number of cases and give rise to more occurrence of complications, including poor wound healing, infection, formation of lymphocyst and chronic lymphedema of lower extremities, which would influence the quality of patients' daily life[5, 7,17$]$. Consequently, the lymph node removal is still controversial for 
OC patients. In addition, with the development of minimally invasive surgical treatment and the objective existence of complications of lymph node resection, more and more gynecological oncologists focused on appropriate, reasonable, and accurate lymphadenectomy in OC. Therefore, identifying cases which present LNM would avoid unnecessary systemic lymph node resection and enable the oncologist to provide a better selection of cases. It would not only ensure patient outcomes but also reduced the incidence of complications.

In order to assess the possibility of LNM, several researchers make efforts using different methods. Signorelli et al. used positron emission computed tomography (PECT) to detect potential positive lymph nodes. The study found that the detectable rate of positive lymph nodes was about $83.3 \%$. Signorelli et al. concluded that PECT was safe and reliable for detecting potential positive lymph nodes and could help avoid systematic lymph node dissection[10]. The sentinel node detection was another promising method for identifying LNM in OC patients. The sentinel node detection is still under evaluation in OC patients before it was as part of the standard therapeutic protocol, despite the method using for breast cancer and cervical cancer[7, 18, 19,20]. Bogani et al. developed a nomogram to identify LNM and found that high-grade serous histology was a strongest predictor for $\operatorname{LNM}[5,21]$. Zhou et al. found that poorly differentiation, serous histology, and higher values of CA125 may be associated LNM[22]. In our study, we found that endometrioid carcinoma, a lower degree of differentiation, and positive serum CA125 were all associated with higher occurrence of LNM, which was similar with the conclusion published by Hengeveld in 2019. Hengeveld et al. also found that higher age and the postmenopausal status were significantly associated LNM[23]. However, in our study, we found that the older age was negatively associated with LNM.

\section{Conclusions}

The multivariate logistic regression showed that age, histology type, histology grade and preoperative serum CA125 level were all significant predictors of LNM. After internal and external verification, we found the nomogram established using the above variables has great performance for clinical applying.

\section{Abbreviations}

LNM: lymph node metastases; OC: ovarian carcinoma; ROC: receiver operating characteristic; SEER: Surveillance, Epidemiology, and End Results; VIF: variance inflation factor; OR: Odds Ratio; AUC: Area Under the Curve; PLR: positive likelihood ratio; NLR: negative likelihood ratio; DOR: Diagnostic Odds Ratio; PECT: positron emission computed tomography

\section{Declarations}

\section{Acknowledgments}

None 


\section{Conflict of Interest}

The authors declare that they have no conflict of interest.

\section{Authorship statement}

All authors take responsibility for the integrity and the accuracy of this manuscript. Study concept and design, Draft of the manuscript: Wei Ren; Acquisition of data, Statistical analysis, Edit: Guiping Zhang.

\section{Conflicts of Interest and Source of Funding}

All authors certify that they have no affiliations with or involvement in any organization or entity with any financial interest (such as honoraria; educational grants; participation in speakers' bureaus; membership, employment, consultancies, stock ownership, or other equity interest; and expert testimony or patentlicensing arrangements), or non-financial interest (such as personal or professional relationships, affiliations, knowledge, or beliefs) in.

\section{References}

1. Miree O, Srivastava SK, Dasgupta S, Singh S, Rocconi R, Singh AP (2021) Current and futuristic roadmap of ovarian cancer management: An overview. Adv Exp Med Biol 1330:1-19. DOI 10.1007/978-3-030-73359-9_1

2. Leandersson P, Hogberg T, Dickman PW, Malander S, Borgfeldt C (2021) Incidence and survival of epithelial ovarian, fallopian tube, peritoneal, and undesignated abdominal/pelvic cancers in sweden 1960-2014: A population-based cohort study. BMC Cancer 21(1):465. DOI 10.1186/s12885-02108169-w

3. Kornovski Y, Ivanova Y, Kostov S, Slavchev S, Yordanov A (2021) Gynaecological oncologic diseases and pregnancy. Wiad Lek 74(8):1984-1987

4. Zheng MJ, Li X, Hu YX, Dong H, Gou R, Nie X, Liu Q, Ying-Ying H, Liu JJ, Lin B (2019) Identification of molecular marker associated with ovarian cancer prognosis using bioinformatics analysis and experiments. J Cell Physiol 234(7):11023-11036. DOI 10.1002/jcp.27926

5. Bogani G, Tagliabue E, Ditto A, Signorelli M, Martinelli F, Casarin J, Chiappa V, Dondi G, Leone Roberti Maggiore U, Scaffa C, Borghi C, Montanelli L, Lorusso D, Raspagliesi F (2017) Assessing the risk of pelvic and para-aortic nodal involvement in apparent early-stage ovarian cancer: A predictors- and nomogram-based analyses. Gynecol Oncol 147(1):61-65. DOI 10.1016/j.ygyno.2017.07.139

6. Rusu MC, Ilie AC, Brezean I (2017) Human anatomic variations: Common, external iliac, origin of the obturator, inferior epigastric and medial circumflex femoral arteries, and deep femoral artery course on the medial side of the femoral vessels. Surg Radiol Anat 39(11):1285-1288. DOI $10.1007 /$ s00276-017-1863-6

7. Van NT, Nguyen-Xuan HT, Koual M, Bentivegna E, Bats AS, Azaïs H (2021) [sentinel lymph node biopsy in the management of early-stage ovarian cancer: A systematic review of the literature.]. 
Gynecol Obstet Fertil Senol. 10.1016/j.gofs.2021.09.011

8. Brezean I, Aldoescu S, Catrina E, Vâlcu M, Ionuţ I, Predescu G, Degeratu D, Pantea I (2010) Pelvic and abdominal-wall actinomycotic infection by uterus gateway without genital lesions. Chirurgia (Bucur) 105(1):123-125

9. Gallotta V, Ghezzi F, Vizza E, Chiantera V, Ceccaroni M, Franchi M, Fagotti A, Ercoli A, Fanfani F, Parrino C, Uccella S, Corrado G, Scambia G, Ferrandina G (2014) Laparoscopic staging of apparent early stage ovarian cancer: Results of a large, retrospective, multi-institutional series. Gynecol Oncol 135(3):428-434. DOI 10.1016/j.ygyno.2014.09.006

10. Signorelli M, Guerra L, Pirovano C, Crivellaro C, Fruscio R, Buda A, Cuzzucrea M, Elisei F, Ceppi L, Messa C (2013) Detection of nodal metastases by $18 \mathrm{f}-\mathrm{fdg}$ pet/ct in apparent early stage ovarian cancer: A prospective study. Gynecol Oncol 131(2):395-399. DOI 10.1016/j.ygyno.2013.08.022

11. Bacalbasa N, Balescu I, Vilcu M, Dima S, Diaconu C, Iliescu L, Filipescu A, Dimitriu M, Brezean I (2020) The risk of para-aortic lymph node metastases in apparent early stage ovarian cancer. Medicina (Kaunas) 56(3). DOI 10.3390/medicina56030108

12. Sasano T, Gonzalez-Delgado R, Muñoz NM, Carlos-Alcade W, Cho MS, Sheth RA, Sood AK, AfsharKharghan V (2021) Podoplanin promotes tumor growth, platelet aggregation, and venous thrombosis in murine models of ovarian cancer. J Thromb Haemost DOI. 10.1111/jth.15544

13. Luengas-Wuerzinger V, Rawert F, C.-V.O.N.S. S S, Baransi E, Schuler K, Carrizo P, Mallmann, Lampe B (2021) Role of the cardiophrenic lymph node status after neoadjuvant chemotherapy in primary advanced ovarian cancer. Anticancer Res 41(10):5025-5031. DOI 10.21873/anticanres.15317

14. Durmuş Y, Meydanlı MM, Akıllı H, Kayıkçıoğlu F, Güngördük K, Akbayır Ö, Taşkın S, Çelik H, Ayhan A (2021) Factors associated with the involvement of lymph nodes in low-grade serous ovarian cancer. J Surg Oncol. DOI 10.1002/jso.26700

15. Nasioudis D, Latif NA, Haggerty AF, Giuntoli li RL, Kim SH, Ko EM (2021) Outcomes of comprehensive lymphadenectomy for patients with advanced stage ovarian carcinoma and rare histologic subtypes. Int J Gynecol Cancer 31(8):1132-1136. DOI 10.1136/ijgc-2021-002559

16. Nasioudis D, Albright BB, Ko EM, Haggerty AF, Giuntoli li RL, Kim SH, Morgan MA, Latif NA (2021) Oncologic outcomes of minimally invasive versus open radical hysterectomy for early stage cervical carcinoma and tumor size $<2 \mathrm{~cm}$ : A systematic review and meta-analysis. Int $\mathrm{J}$ Gynecol Cancer 31(7):983-990. DOI 10.1136/ijgc-2021-002505

17. Maggioni A, Benedetti Panici P, Dell'Anna T, Landoni F, Lissoni A, Pellegrino A, Rossi RS, Chiari S, Campagnutta E, Greggi S, Angioli R, Manci N, Calcagno M, Scambia G, Fossati R, Floriani I, Torri V, Grassi R, Mangioni C (2006) Randomised study of systematic lymphadenectomy in patients with epithelial ovarian cancer macroscopically confined to the pelvis. Br J Cancer 95(6):699-704. DOI $10.1038 /$ sj.bjc. 6603323

18. Lago V, Montero B, López S, Padilla-Iserte P, Matute L, Marina T, Gurrea M, Montoliu G, Bello P, Domingo $S$ (2021) Ultrastaging protocol in sentinel lymph node for apparent early stage ovarian cancer. Gynecol Oncol 161(2):408-413. DOI 10.1016/j.ygyno.2021.03.001 
19. Balaya V, Lecuru F, Laas E (2021) How to perform sentinel node detection in high-risk endometrial cancer: One step forward. J Gynecol Oncol 32(4):e71. DOI 10.3802/jgo.2021.32.e71

20. Backes FJ, Felix AS, Plante M, Grégoire J, Sullivan SA, Rossi EC, Tanner EJ 3, Stewart KI, Soliman PT, Holloway RW, Abu-Rustum NR, Leitao MM Jr (2021) Sentinel lymph node (sln) isolated tumor cells (itcs) in otherwise stage i/ii endometrioid endometrial cancer: To treat or not to treat? Gynecol Oncol 161(2):347-352. DOI 10.1016/j.ygyno.2021.02.017

21. Bogani G, Tagliabue E, Signorelli M, Ditto A, Martinelli F, Chiappa V, Mosca L, Sabatucci I, Leone Roberti Maggiore U, Lorusso D, Raspagliesi F (2018) A score system for complete cytoreduction in selected recurrent ovarian cancer patients undergoing secondary cytoreductive surgery: Predictorsand nomogram-based analyses. J Gynecol Oncol 29(3):e40. DOI 10.3802/jgo.2018.29.e40

22. Zhou J, Sun JY, Wu SG, Wang X, He ZY, Chen QH, Li FY (2016) Risk factors for lymph node metastasis in ovarian cancer: Implications for systematic lymphadenectomy. Int J Surg 29:123-127. DOI 10.1016/j.ijsu.2016.03.039

23. Hengeveld EM, Zusterzeel PLM, Lajer H, Høgdall CK, Rosendahl M (2019) The value of surgical staging in patients with apparent early stage epithelial ovarian carcinoma. Gynecol Oncol 154(2):308-313. DOI 10.1016/j.ygyno.2019.06.006

\section{Figures}




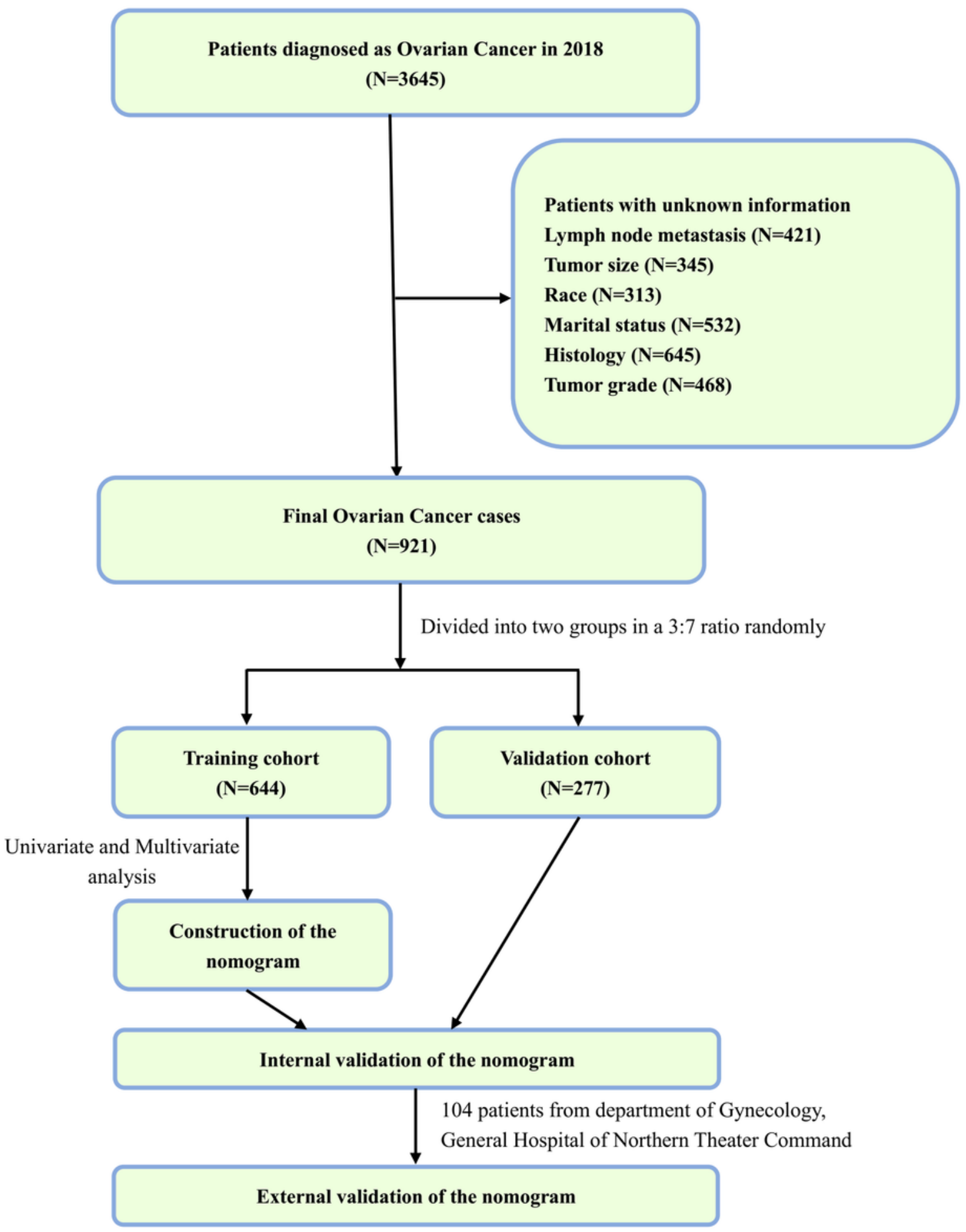

\section{Figure 1}

Flow chart for $\mathrm{OC}$ patients in training and validation cohorts. 


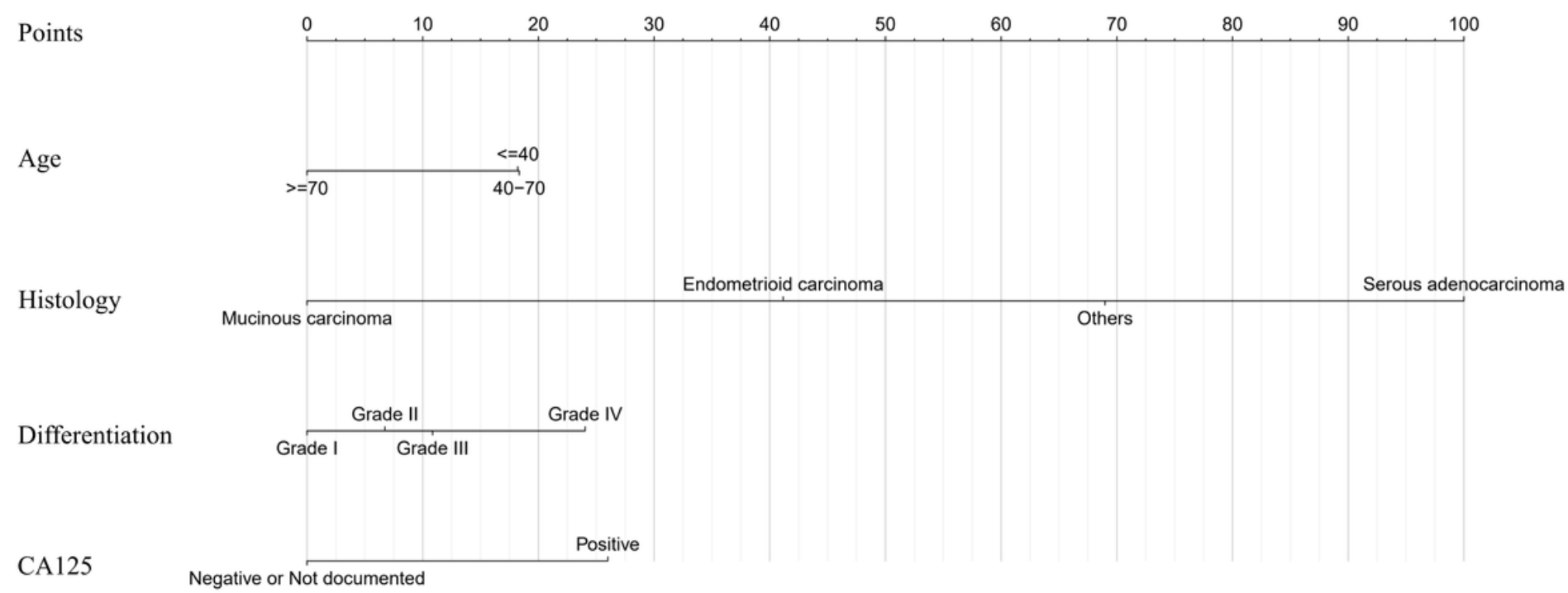

Total Points
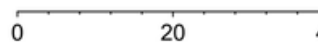

$40+60$

80

100

140

160

Disease risk

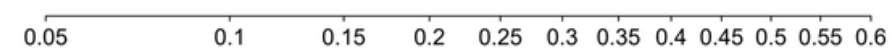

\section{Figure 2}

The nomogram to predict the probability of LNM in patients with OC. Based on the risk factors selected, we developed a nomogram to predict the probability of LNM based on the logistic model. 
A

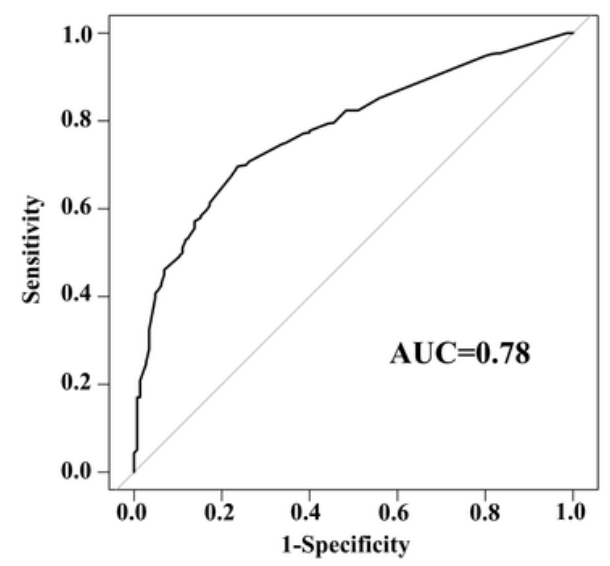

D

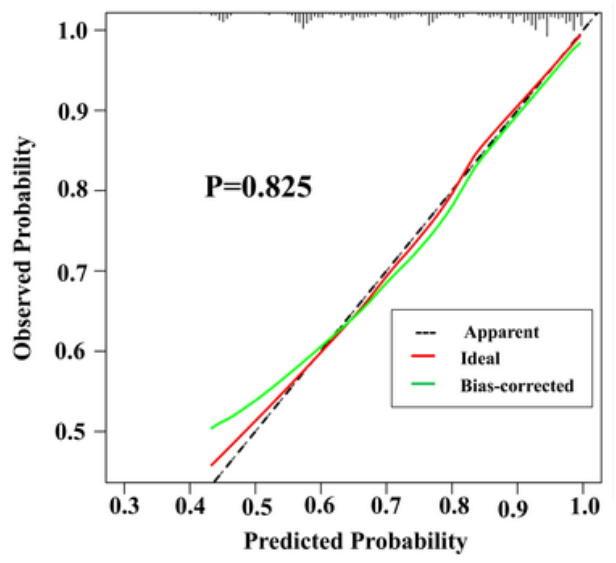

G

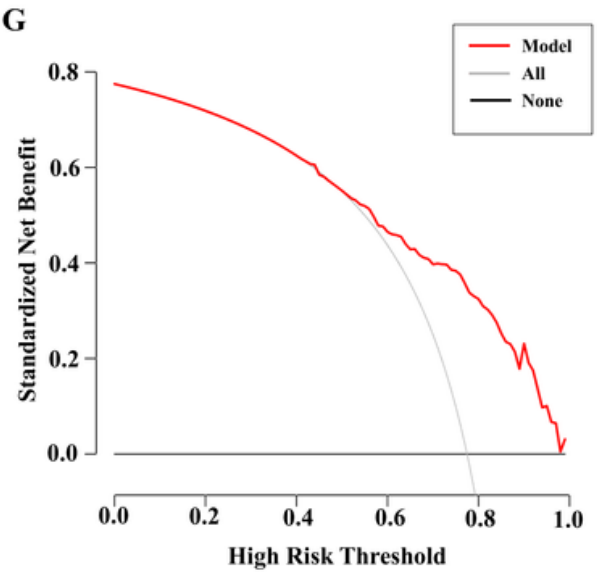

B

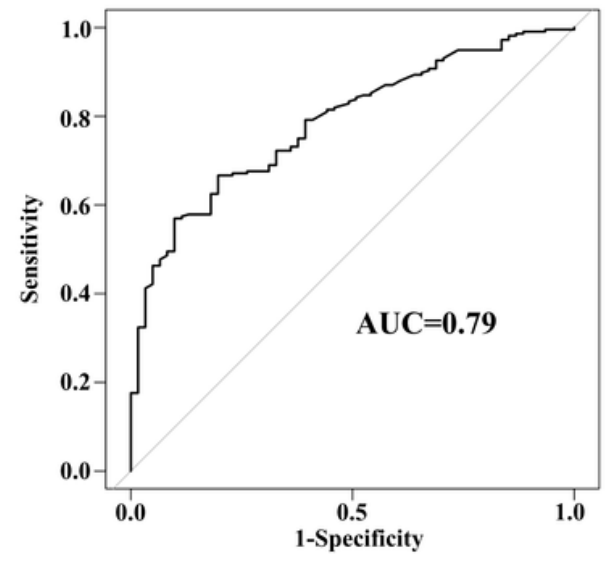

E

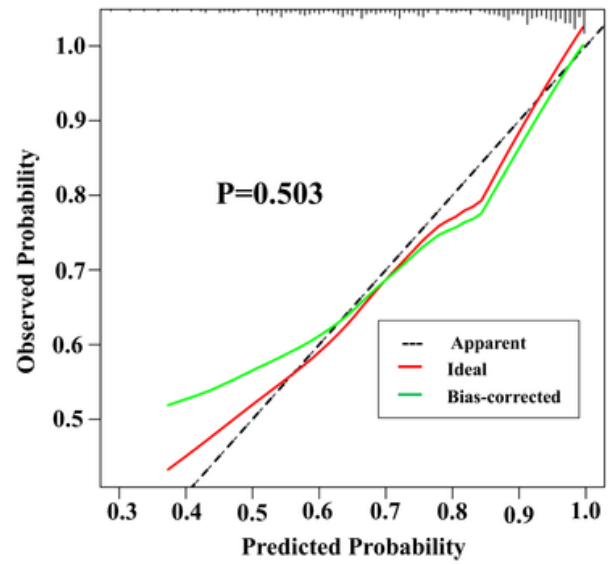

H

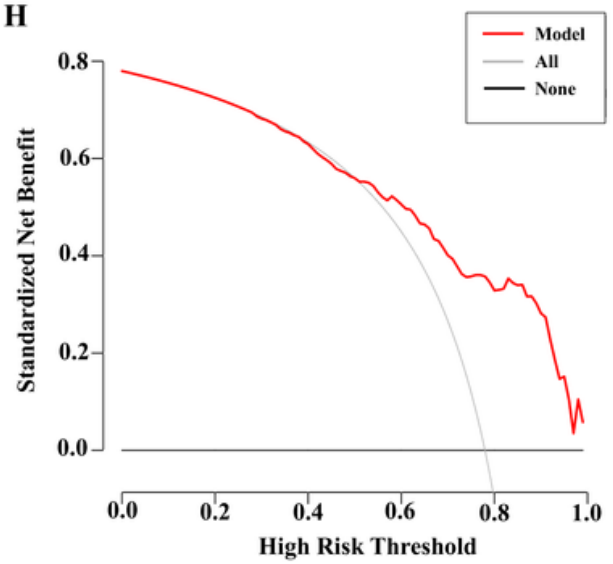

C

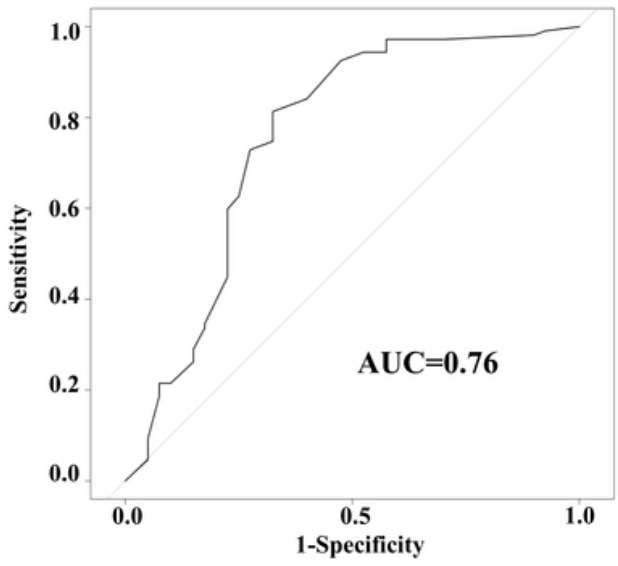

F

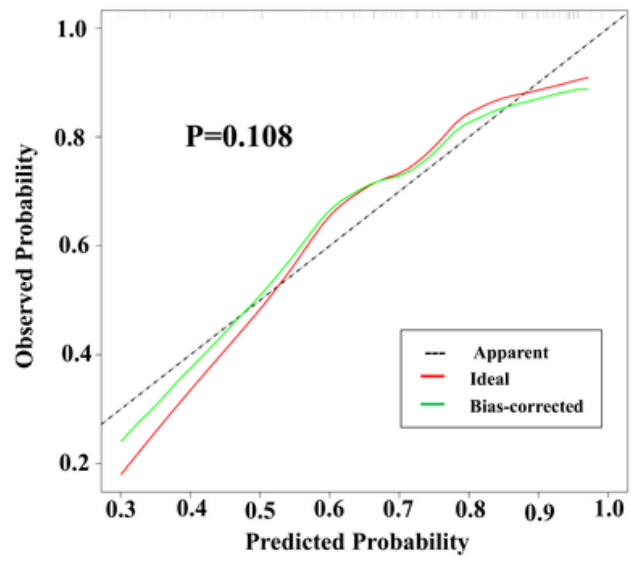

I

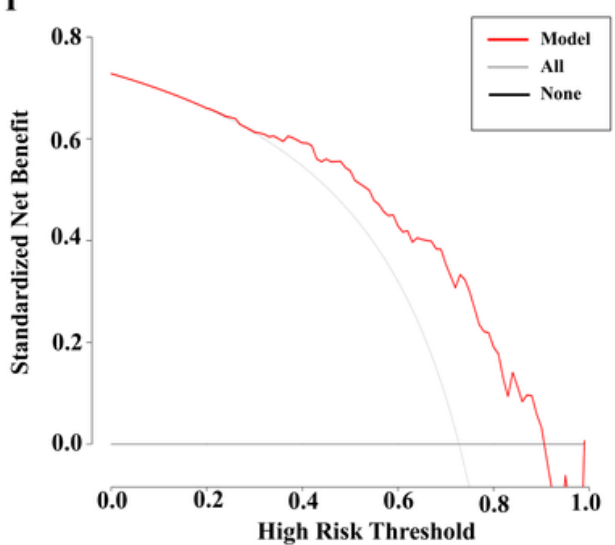

Figure 3

Nomogram Validation The AUC of the model training cohort, internal validation cohort, and external validation cohort were 0.78 (figure3A), 0.79 (figure3B) and 0.76 (figure3C) respectively, which indicated favorable discrimination. The calibration curves showed that the predicted outcome fitted well to the observed outcome in the training cohort ( $p=0.825$, figure3D) internal validation cohort $(p=0.503$, figure3E), and external validation cohort ( $\mathrm{p}=0.108$, figure3F). The decision curves showed the nomogram had more benefits than the All or None scheme if the threshold probability is $>50 \%$ and $<100 \%$ in training cohort and internal validation cohort (figure3G, H), $>30 \%$ and $<90 \%$ in the external validation cohort (figure3I). 


\section{Supplementary Files}

This is a list of supplementary files associated with this preprint. Click to download.

- supplementarytable1.docx

- supplementarytable2.docx 